\title{
Eplerenone Suppresses Salt-Induced Vascular Endothelial Growth Factor Expression in the Kidney
}

\author{
Danita Eatman Mohammed F. Layas Mohamed A. Bayorh \\ Department of Pharmacology and Toxicology, Morehouse School of Medicine, Atlanta, Ga., USA
}

\section{Key Words}

Mineralcorticoid receptor antagonist - Hypertension •

Nitric oxide synthase $\cdot$ Dahl rat

\begin{abstract}
Background/Aim: It is well accepted that high dietary salt intake accelerates both hypertension and target organ damage. We have previously shown that eplerenone attenuates sustained elevated systolic blood pressure in Dahl salt-sensitive (SS) rats. In the present study, we investigated the role of eplerenone on vascular endothelial growth factor (VEGF) expression because we suspected that eplerenone treatment may trigger a unique mechanism that relies on the downregulation of VEGF. Methods: Dahl SS rats were fed a high salt $(8 \% \mathrm{NaCl})$ diet for 3 weeks and then switched to normal salt $(0.3 \% \mathrm{NaCl})$ diet with or without treatment with eplerenone (100 mg/kg/day), enalapril (30 mg/kg/day) and their combination for an additional 3 weeks. Results: In addition to reducing blood pressure, eplerenone inhibited glomeruli sclerosis and suppressed the expression of VEGF and endothelial nitric oxide synthase mRNA as well as protein levels. Conclusions: Based on these findings, we suggest that in part, VEGF stimulation of endothelial nitric oxide synthase plays a significant role in the eplerenone-induced reversal of the renal and vascular damage caused by high dietary salt intake.

Copyright $\odot 2010$ S. Karger AG, Basel
\end{abstract}

\section{Introduction}

It is well accepted that high dietary salt intake accelerates both hypertension and target organ damage. Furthermore, there is compelling evidence that normal or increased salt intake results in marked damage to renal tissues via the mineralcorticoid receptor [1]. We previously reported that the administration of high dietary salt to the Dahl salt-sensitive (SS) rat results in an increase in angiotensin II which causes an increase in aldosterone levels [2]. Clinical and preclinical studies have linked elevated aldosterone to hypertension, left ventricular and vascular remodeling. Also, cardiac, renal, and cerebral vascular inflammation and injury, and increased risk of mortality in heart failure patients are associated with elevated aldosterone levels [3].

More recently, aldosterone receptor antagonists as well as angiotensin II converting enzyme (ACE) inhibitors and angiotensin receptor blockers have been shown to markedly reduce enhanced elevation in blood pressure and the severity of renal damage [4]. Eplerenone, a new and more selective mineralcorticoid receptor antagonist with fewer side effects than spironolactone, has been reported to retard the development of vascular inflammation, endothelial dysfunction and myocardial fibrosis [5, 6]. Multiple studies in experimental models of hypertension and heart failure demonstrate that selective blockade

\section{KARGER}

(C) 2010 S. Karger AG, Basel

Fax +4161306 1234

E-Mail karger@karger.ch

www.karger.com
Mohamed A. Bayorh, PhD

720 Westview Drive, Research Wing \#306

Atlanta, GA 30310 (USA)

Tel. +1 404752 1714, Fax +1 4047521164

E-Mail mbayorh@msm.edu 
of aldosterone by eplerenone effectively preserves cardiac function, attenuates maladaptive left ventricular remodeling and tissue and vascular injury in part by reducing vascular inflammation in aldosterone target organs [79]. The major adverse effects of aldosterone involve the induction of vascular inflammation and fibrinoid necrosis of small arteries and arterioles and endothelial dysfunction.

Interestingly in hypertension, endothelial dysfunction is associated with elevated vascular endothelial growth factor (VEGF) levels [10]; this potent cytokine has been shown to enhance the production of endothelium-derived vasoactive factors such as prostacyclin and nitric oxide (NO) and regulates multiple biological functions including inhibiting thrombosis and causing vasorelaxation [11]. VEGF is an established and potent angiogenic factor that is thought to play a key role in cardiovascular disease [12]. Also, it has been suggested that VEGF could serve as a marker for early organ damage in hypertension [13].

Based on these observations, we investigated the role of eplerenone on VEGF expression because we suspected that eplerenone treatment may trigger a unique mechanism that relies on the downregulation of VEGF and/or the upregulation of heat-shock proteins (HSPs). Also in the present study, we examined the effect of eplerenone alone and in combination with the ACE inhibitor, enalapril on histopathological changes in the kidney in hypertensive Dahl rats so that we may better understand the mechanisms underlying the role of eplerenone in the renal protection in the Dahl salt-induced hypertensive rats.

\section{Materials and Methods}

\section{Experimental Design}

Male Dahl SS rats (4-5 weeks, Harlan Sprague-Dawley, Indianapolis, Ind., USA) were grouped 5 per cage in the animal facility with 12-hour light/dark cycles with the temperature controlled at $21-23^{\circ} \mathrm{C}$. Food and water were available ad libitum. Following acclimatization, the animals were put in individual cages and fed a high salt diet $(8 \% \mathrm{NaCl})$ for 3 weeks. They were then switched to a normal salt $(0.3 \% \mathrm{NaCl})$ diet for 3 more weeks with or without treatment with (1) enalapril (30 mg/kg/day in the drinking water); (2) eplerenone (100 $\mathrm{mg} / \mathrm{kg} /$ day by gavage), and (3) enalapril + eplerenone. Prior to (basal) and weekly thereafter, systolic blood pressure and heart rate were measured indirectly. After these measurements at 3 weeks, each animal was anesthetized (70 mg/ $\mathrm{kg}$ ketamine and $10 \mathrm{mg} / \mathrm{kg}$ xylazine, i.m.) and the kidneys were harvested. There were 7 rats/group. The 0.3 and $8 \% \mathrm{NaCl}$ diets were purchased from Harlan (Madison, Wisc., USA). In a separate study, Dahl SS rats were fed either a low salt or high salt diet alone (LS, HS) for 3 weeks then eplerenone (100 mg/kg/day) was given for an additional 3 weeks (LS/EPL, HS/EPL). The rats fed the low or normal salt diet $(0.3 \% \mathrm{NaCl})$ served as the control. Blood pressure was measured as described above and tissue samples collected for Western blot analysis and plasma and urine sample stored at $-80^{\circ} \mathrm{C}$.

Indirect Blood Pressure Measurement in Conscious Rats

A noninvasive blood pressure acquisition system for rats (The CODA 2 System from Kent Scientific, Torrington, Conn., USA) was used to measure systolic blood pressure and heart pulse rate.

\section{Tissue Harvesting and Histopathology}

Both kidneys were harvested from all animals, either stored in formalin (histopathology studies) or frozen in liquid nitrogen (gene expression studies) and stored at $-80^{\circ} \mathrm{C}$. The heart and kidney wet weights were measured.

The kidneys from control, ENA, EPL and ENA + EPL rats (4 per group) were fixed in Lillie's $10 \%$ neutral buffered formalin phosphate and shipped to Histo-Scientific Research Laboratories, Inc. (Mount Jackson, Va., USA) for the preparation of histological slides. The organs were embedded in paraffin. The paraffin blocks were cut into 4 - $\mu \mathrm{m}$ thick slices and stained with hematoxylin and eosin (HE) and with periodic acid-Schiff. The prepared slides were examined and evaluated microscopically in a blinded fashion for pathologic lesions. A minimum of 10 highpower fields was examined for each slide. For the kidney sections, the proportions of glomeruli with pathologic lesions to the total number of glomeruli, the proportions of arteries/arterioles with pathologic lesions to the total number of arteries/arterioles, and the proportions of tubules with pathologic lesions to the total number of tubules were noted for each slide and scored on a scale of $0-5$, where $0=$ none; $1=\operatorname{minimal} ; 2=\operatorname{mild} ; 3=$ moderate $4=$ marked; 5 = severe for all rats, and then averaged. Representative photomicrographs were taken from each slide for comparison among the groups.

RNA Isolation and Microarray Analysis

Total RNA was isolated from heart and kidney using TRIzol reagent (Gibco-BRL). The RNA sample was stored at $-80^{\circ} \mathrm{C}$ until used. Total RNA concentration was determined by measuring the absorbance at $260 \mathrm{~nm}$. Total RNA was visualized by agarose gel electrophoresis.

The staff in the Functional Genomics Laboratory at Morehouse School of Medicine performed the microarray analysis. Briefly, The Atlas Image 1.0 (Clontech) software was used to compare gene expression profiles between RNA isolated from Dahl SS rat kidney samples. The tissue used for this analysis was taken from 3 of 7 rats in each treatment group. Comparisons of rats exposed to antihypertensive agents (i.e. enalapril, eplerenone) versus those exposed to no drug (control) were performed with significance analysis of microarrays to identify genes with a change of more than 1.5-fold. Signal intensities between the compared arrays were normalized using the Global Mode (to develop a normalization coefficient), which uses an average value based on all the bands. A fold change $>1$ signifies an upregulation while a fold change $<1$ indicates a downregulation of that gene.

Protein Purification and Western Blot Analysis

Protein was isolated through homogenization of the kidney in the lysis buffer (Invitrogen) containing protease inhibitors 
(Sigma-Aldrich). The supernatant was collected and stored on ice for protein determination (by Bradford assay). The proteins were separated by SDS-PAGE. After electrophoresis separation, proteins were transferred to a nitrocellulose membrane by electroblotting, and membranes incubated as described in the Western Breeze Chemiluminescent kit (Invitrogen). The membrane was probed with antibodies to rat VEGF and rat endothelial nitric oxide synthase (eNOS) (1:100 dilutions; Santa Cruz Biotechnology). Densitometry units were normalized to actin. Each lane in a blot represented tissue lysate from 1 rat. Fold changes between treatment groups were calculated from individual blots, and mean changes were derived from replicates. Bands were visualized with a luminoanalyzer and band intensity was calculated with Image software $(\mathrm{NIH})$ and expressed as integrated density.

\section{Statistical Analysis}

Values are reported as mean \pm SEM, where $n$ refers to the number of rats used. Statistical significance $(p<0.05)$ was evaluated using analysis of variance (ANOVA) followed by the TukeyKramer multiple comparison test.

\section{Results}

\section{Effect of Eplerenone and/or Enalapril on Systolic}

Blood Pressure

Systolic blood pressure was significantly elevated following 3 weeks on a high salt $(8 \% \mathrm{NaCl})$ diet (from 128 \pm 3 to $233 \pm 5 \mathrm{~mm} \mathrm{Hg}, \mathrm{n}=34$; data not shown). Table 1 demonstrates that once rats were removed from high salt diet and switched to low salt diet for 3 weeks, blood pressure remained elevated. When compared to the rats on a low salt diet and no drug treatment (control), eplerenone and enalapril caused a significant reduction in blood pressure. The average systolic blood pressure in the enalapril-treated rats was $25 \pm 3 \mathrm{~mm} \mathrm{Hg}$ lower than the rats that received no drugs. The rats treated with eplerenone had the greatest reduction ( $43 \pm 3 \mathrm{~mm} \mathrm{Hg}$ ) in blood pressure when compared to control (table 1).

\section{Effect of Eplerenone and/or Enalapril on Tissue Damage}

The results of the histopathology evaluation of the kidney of the three groups of rats studied are summarized in table 2. Microscopic examination of the kidney sections from SS rats fed 3 weeks high salt diet followed by 3 weeks low salt diet (control) showed severe focal glomerulosclerosis (fig. 1a), moderate thickening of glomerular capillary wall, moderate atherosclerosis and mild hyperplastic arteriolosclerosis. The histopathology changes in the kidney sections from SS rats treated with enalapril showed mild focal glomerulosclerosis (fig. 1b), mild thickening of glomerular capillary wall and mild
Table 1. Systolic blood pressure measured after 3 weeks on a high salt diet (HS; $8 \% \mathrm{NaCl}$ ) and 3 weeks after switching to a low salt $\operatorname{diet}(\mathrm{LS} ; 0.3 \% \mathrm{NaCl}$ ) with or without drug treatment

\begin{tabular}{llll}
\hline Treatment & \multicolumn{2}{l}{ Systolic blood pressure, mm Hg } & $\begin{array}{l}\text { Body } \\
\text { weight }\end{array}$ \\
\cline { 2 - 3 } & $\begin{array}{l}\text { 3 weeks } \\
\text { of HS }\end{array}$ & $\begin{array}{l}\text { 3 weeks on LS } \\
\text { treatment }\end{array}$ & $\mathrm{g}$ \\
\hline Control & $206 \pm 11$ & $198 \pm 10$ & $325 \pm 19$ \\
Enalapril (ENA) & $201 \pm 11$ & $176 \pm 9^{*}$ & $337 \pm 19$ \\
Eplerenone (EPL) & $201 \pm 13$ & $158 \pm 8^{*, \#}$ & $358 \pm 20$ \\
ENA + EPL & $203 \pm 12$ & $157 \pm 8^{*, \#}$ & $345 \pm 13$
\end{tabular}

Data are represented as mean \pm SEM for 6-7 animals per group. Significant difference $(p<0.05)$ from the normal salt control, or enalapril is denoted by ${ }^{*}$ and ${ }^{\#}$, respectively.

atherosclerosis. In contrast, the kidney sections from SS rats treated with eplerenone (fig. 1c) only or in combination with enalapril (data not shown) showed no significant histopathology changes. Quantitatively the glomeruli sclerosis was severe in the control $(60 \pm 8 \%)$ versus enalapril (16 $\pm 3 \%$ ), and eplerenone alone or in combination with enalapril (no sclerosis noted). Data reflect the mean measurement from 4 rats/group.

\section{Effect of Eplerenone on VEGF and eNOS Expression}

The microarray data were surveyed to identify potential genes that were either up- or downregulated following treatment with eplerenone and/or enalapril. Over 400 genes were positively expressed in rats exposed to drug treatment versus those exposed to no drug, while less than 100 genes were downregulated (data not shown). In the kidney, heat-shock protein 70 (Hsp70) mRNA levels were significantly upregulated and VEGF and NOS3 (eNOS) levels declined following treatment with enalapril, eplerenone, and/or enalapril + eplerenone (table 3).

To further clarify the findings obtained in the microarray, Western blot analysis confirmed that VEGF protein expression was detectable in renal tissue from all groups (fig. 2). VEGF protein levels were significantly higher in kidneys from the hypertensive rats than from rats fed the low salt diet. After eplerenone treatment, VEGF protein expression declined by $57 \pm 1 \%$ in the hypertensive rats; VEGF expression tended to also decline in the rats fed the low salt diet but was not significant $(p>0.05)$. In addition, the detection of the eNOS protein was observed only in the rats fed the high salt diet without eplerenone (fig. 2). 


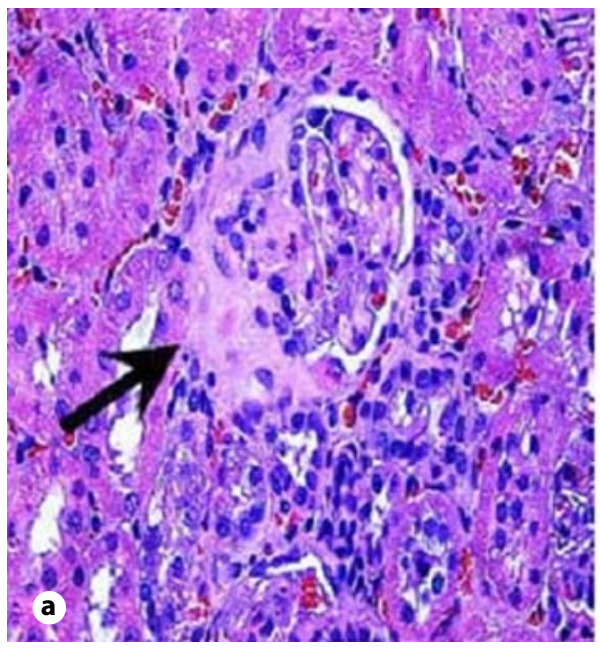

HS/LS

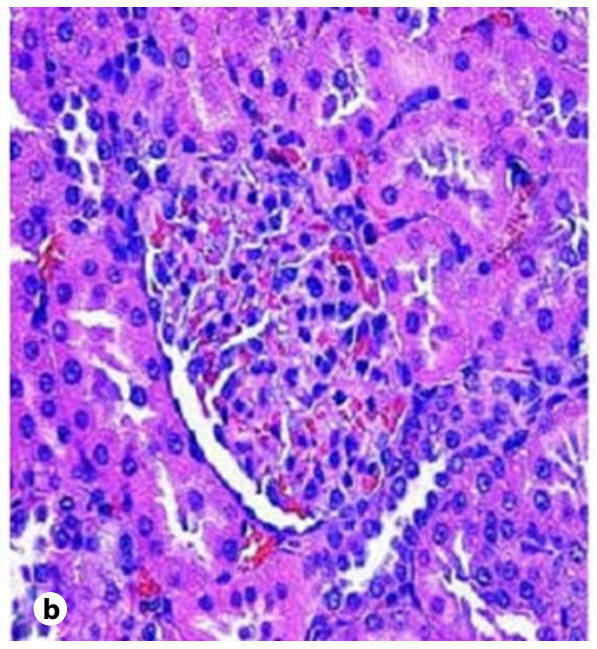

LS/enalapril

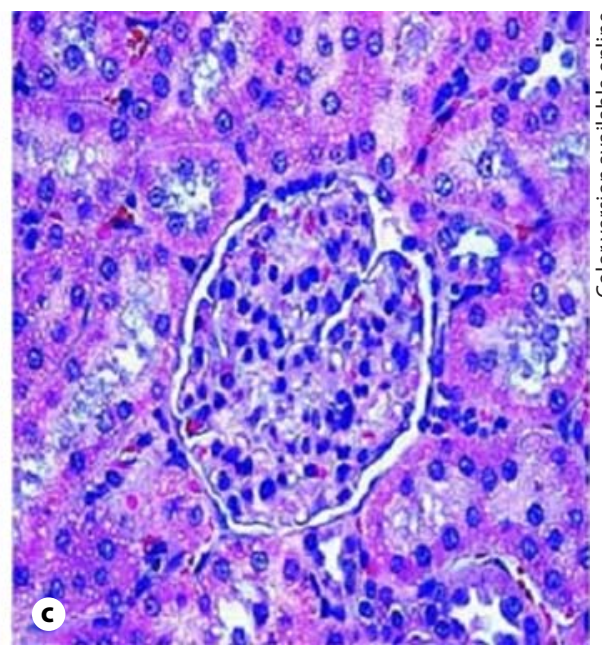

LS/eplerenone
Fig. 1. Glomeruli sclerosis in Dahl SS rats. Photomicrographs (orig. magnif. $\times 200$ ) of the histopathology of HE-stained kidney sections from SS rats fed 3 weeks high salt diet followed by 3 weeks low salt diet (control) with or without drug treatment with enalapril treatment (ENA), eplerenone (EPL), or their combination
$($ ENA + EPL). Sections shown are typical of the 4 rats/group. a Control sections showing severe focal glomerulosclerosis (arrow highlights glomerulosclerosis). b Kidney section from an ENAtreated rat showing mild focal glomerulosclerosis. c Section from an EPL-treated rat showing no histopathologic changes.

Table 2. Histopathologic evaluation of kidneys from control, ENA, EPL and ENA + EPL rats

\begin{tabular}{|c|c|c|c|c|}
\hline Structure and histopathologic lesion ${ }^{\mathrm{a}}$ & Control & ENA & EPL & $\mathrm{ENA}+\mathrm{EPL}$ \\
\hline \multicolumn{5}{|l|}{ Glomeruli } \\
\hline Sclerosis & severe $(60 \pm 8 \%)$ & mild $(16 \pm 3 \%)$ & none & none \\
\hline Fibrinoid necrosis & none & none & none & none \\
\hline Capillary wall thickening & moderate & mild & none & none \\
\hline \multicolumn{5}{|l|}{ Renal vessels } \\
\hline Atherosclerosis & moderate & mild & none & none \\
\hline Hyperplastic arteriolosclerosis & mild (17 $\pm 3 \%)$ & none & none & none \\
\hline
\end{tabular}

Control group was fed a $8 \% \mathrm{NaCl}$ diet for 3 weeks then switched to a $0.3 \% \mathrm{NaCl}$ diet without drug treatment with enalapril (ENA), eplerenone (EPL) or the combination (ENA + EPL). Values in parentheses are mean percentages \pm SEM. ${ }^{\text {a }}$ Four rats were evaluated per group.

Table 3. Effect of EPL, ENA, and their combination on mRNA expression of VEGF eNOS and HSP in the kidney

\begin{tabular}{llll}
\hline Treatment & VEGF & eNOS & HSP70 \\
\hline Enalapril (ENA) & $\leftrightarrow$ & $\uparrow$ & $\uparrow$ \\
Eplerenone (EPL) & $\downarrow$ & $\downarrow$ & $\uparrow$ \\
ENA + EPL & $\downarrow$ & $\downarrow$ & $\uparrow$ \\
\hline
\end{tabular}

VEGF = Vascular endothelial growth factor; eNOS = endothelial nitric oxide synthase; HSP70 = heat-shock protein 70 .

$\leftrightarrow=$ No change; $\downarrow=$ decreased; $\uparrow=$ increased. 


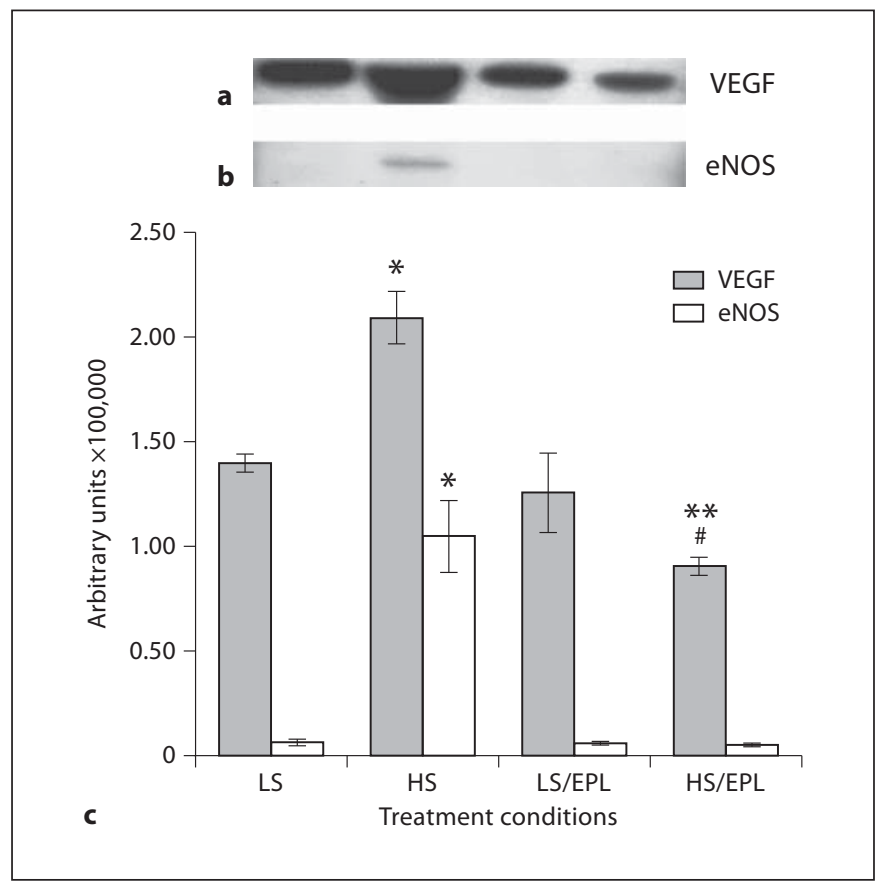

Fig. 2. Renal VEGF and eNOS protein expression in Dahl SS rats fed a low or high salt diet with eplerenone (100 mg/kg/day). Representative Western blot of a VEGF, $\mathbf{b}$ eNOS, and $\mathbf{c}$ relative VEGF and eNOS content (arbitrary units). Densitometry units were normalized to actin. Data represent the mean \pm SEM of three replicates. ${ }^{*} \mathrm{p}<0.05$ when compared to LS; ${ }^{* *} \mathrm{p}<0.05$ when compared to $\mathrm{LS} / \mathrm{EPL} ;{ }^{*} \mathrm{p}<0.05$ when compared to HS.

\section{Discussion}

We have previously reported that switching a hypertensive Dahl SS rat from a high salt diet to a low salt diet with antihypertensive treatment leads to a reduction in blood pressure [14]. This reduction in blood pressure observed with eplerenone treatment led us to further investigate the mechanism by which eplerenone exerts its beneficial effects. SS Dahl rats show severe cardiovascular damage, ventricular hypertrophy and glomerulosclerosis in response to a high salt diet. In the present study, eplerenone diminished the renal damage produced by high dietary salt intake. In addition, eplerenone blocked the rise in the potent angiogenic factor, VEGF protein expression in the kidney. Also, the effect of eplerenone on VEGF expression was correlated with NOS expression.

It is well established that hypertension leads to structural and functional changes in the kidney, which may eventually lead to end-stage renal disease. Managing blood pressure with antihypertensive tends to slow the progression of renal failure, thus reducing the mortality and morbidity rates linked with hypertensive vascular disease [15]. Experimental and clinical studies indicate that aldosterone may add on to the multiple factors that play a role in the induction and maintenance of kidney damage $[16,17]$. Therefore, blocking aldosterone activity via mineralcorticoid receptor using eplerenone could represent a novel therapeutic approach to complement current treatments of chronic kidney disease.

The pathogenesis of target organ damage is also widely believed to be, at least in part, blood pressure-independent and, mediated by the direct tissue-damage-promoting effects of the renin-angiotensin-aldosterone system $[15,18]$. This is based on the fact that ACE inhibitors and angiotensin receptor blockers have been shown to markedly reduce the severity of renal damage without significantly reducing blood pressure [19-22]. Rocha et al. [23] have shown that selective aldosterone blockade prevents angiotensin II and/or salt-induced vascular inflammation. In the present study, the reduction in blood pressure produced by eplerenone was associated with a reduction in renal injury in these rats. Our findings are in agreement with those of Nagase et al. [24] which showed that in the Dahl salt-hypertensive rats, eplerenone lowered systemic blood pressure, reduced podocyte damage, and slowed the development of proteinuria and glomerulosclerosis. Likewise, in the nephrectomy rat model, treatment with spironolactone was associated with regression of glomerulosclerosis in 33\% of animals when used alone; this percentage increased when conventional antihypertensive therapy or losartan were added [25]. In the hypertensive Dahl rats, treatment with enalapril was associated with mild glomerulosclerosis when used alone; however, with the addition of eplerenone with enalapril, there appeared to be little or no evidence of sclerosis of the glomeruli. The suppression of renal injury was more pronounced when the hypertension was treated with eplerenone than with enalapril which led us to take a closer look at the mechanism of action of eplerenone.

To explore the potential mechanisms by which eplerenone and enalapril attenuate nephropathy, the microarray analysis was used to identify those genes involved in inflammation. Several novel genes involved in inflammatory processes and vascular wall cell proliferation such as VEGF, eNOS and Hsp70 were differentially expressed. We observed a greater regulation of these genes when rats were treated with eplerenone than with enalapril. VEGF was initially described as an endothelial cellspecific growth factor that stimulates endothelial prolif- 
eration, migration, and NO release in vitro. Others have shown that VEGF regulates the expression of several genes, such as NOS, tissue factor, anti-apoptotic proteins, and matrix-degrading metalloproteinase [26, 27]. The protein levels of VEGF and eNOS were measured to further clarify the microarray data. In the hypertensive rats, we observed that the VEGF protein expression increased. Our findings are consistent with observations in the spontaneously hypertensive rats (SHRs) and transgenic rats (mRen2)-27, which demonstrated an upregulation in VEGF [28]. Also, in human hypertensive patients, plasma VEGF levels are higher than their normotensive counterparts [10]. Treating the hypertension with eplerenone reduced VEGF mRNA and protein levels in the kidney. These findings are similar to other findings reporting that treatment of hypertension significantly reduces plasma VEGF levels [29]. Taken together, the above results suggest that the VEGF pathway plays an important role in hypertension and may be subsequently involved in vascular and renal damage.

VEGF is an established and potent cytokine that exerts several important actions on the vascular endothelium [30]. It is expressed in abundance in the embryo but is downregulated in adults. VEGF's role in pathological angiogenesis has been well documented in various disease models and has been described as a marker for early microvascular and target organ damage in hypertension [10, 29]. To further clarify the role of VEGF in this study, NOS expression was examined. Several studies have reported that VEGF upregulates NOS-II and NOS-III mRNA and protein expression [31-33], which induces NO production. VEGF stimulates endothelial production of $\mathrm{NO}$ and prostacyclin via two tyrosine kinase receptors VEGFR-1 (Flt-1) and VEGFR-2 (KDR/Flk-1) [11, 26]. This could be an important mechanism underlying the stimulation of NO production by VEGF. We observed in the present study that the downregulation of VEGF mRNA as well as protein expression by eplerenone correlated with the reduction in eNOS mRNA and protein expression in the kidney. Previous findings in our laboratory showed that eplerenone increased plasma NO levels [14]. Thus, the increase in NO levels seen in our previous study may not be due to activation of eNOS, but iNOS. Besides, the reduction in VEGF by eplerenone may be due to NO. Others have shown that NO downregulates VEGF in vitro and in vivo [34-36]. Further investigation is underway in our laboratory to determine the role of eplerenone on iNOS and VEGFR-2 expression to better understand the role of VEGF in hypertension, renal damage and endothelial dysfunction.
We suspect that there are other genes involved in the VEGF pathway that are either up- or downregulated during treatment with eplerenone. Among these are the HSPs such as Hsp70 which has shown cytoprotective effects and are important in the fight against inflammatory disorders [37]. The present study found that Hsp70 levels were significantly regulated by eplerenone treatment. HSPs have been reported to protect against environmental stressors and are widely distributed in many cellular compartments [38, 39]. Tazi et al. [40] suggest that VEGF may stimulate NOS activity both dependently and independently of HSP. Further investigations are required to clarify the synergistic effect of Hsp70 and VEGF by elucidating the possible interactions between these molecules.

In summary, we have shown that renal damage in the hypertensive Dahl rat could be prevented by aldosterone receptor antagonists, such as eplerenone. Based on our current findings, we suggest that in part, VEGF stimulation of eNOS plays a significant role in the reversal of the salt-induced renal and vascular damage. Future studies are needed to clarify the role of HSPs in the VEGF-NOS pathway and ascertain whether the eplerenone-induced improvements are tissue-specific. Taken altogether, these investigations suggest that blockade of aldosterone might offer beneficial effects in the treatment of kidney disease.

\section{Acknowledgments}

We would like to thank Dr. Henry B. Armah for his examination and evaluation of the histological slides for pathologic lesions. This study was funded, in part, by NIH/NIDDK Grant 1SC1DK082385 and NIH/NCRR/RCMI Grant G12-RR03034.

References

1 Sanders PW: Salt intake, endothelial cell signaling, and progression of kidney disease. Hypertension 2004;43:142-146.

2 Bayorh MA, Ganafa AA, Emmett N, Socci RR, Eatman D, Fridie IL: Alterations in aldosterone and angiotensin II levels in salt-induced hypertension. Clin Exp Hypertens 2005;4:355-367.

- 3 Cachofeiro V, Miana M, de Las Heras N, Martin-Fernandez B, Ballesteros S, Fernandez-Tresguerres J, Lahera V: Aldosterone and the vascular system. J Steroid Biochem Mol Biol 2008;109:331-335.

$\checkmark 4$ Cortinovis M, Perico N, Cattaneo D, Remuzzi G: Aldosterone and progression of kidney disease. Ther Adv Cardiovasc Dis 2009;3:133. 
$\checkmark 5$ Martinez DV, Rocha R, Matsumura M, Oestreicher E, Ochoa-Maya M, Roubsanthisuk W, Williams GH, Adler GK: Cardiac damage prevention by eplerenone: comparison with low sodium diet or potassium loading. Hypertension 2002;39:614-618.

$\checkmark 6$ McMahon EG: Recent studies with eplerenone, a novel selective aldosterone receptor antagonist. Curr Opin Pharmacol 2001;1: 190-196.

$>7$ Rocha R, Rudolph AE, Frierdich GE, Nachowiak DA, Kekec BK, Blomme EA, McMahon EG, Delyani JA: Aldosterone induces a vascular inflammatory phenotype in the rat heart. Am J Physiol 2002;283:H1802-H1810.

$\checkmark 8$ Rocha R, Stier CT Jr, Kifor I, Ochoa-Maya MR, Rennke H, Williams GH, Adler GK: Aldosterone: a mediator of myocardial necrosis and renal injury. Endocrinology 2000;141: 3871-3878.

$\checkmark 9$ Rocha R, Chander PN, Zuckerman A, Stier CT: Role of aldosterone in renal vascular injury in stroke-prone hypertensive rats. Hypertension 1999;33:232-237.

$\checkmark 10$ Belgore FM, Blann AD, Li-Saw-Hee FL, Beevers DG, Lip GYH: Plasma levels of vascular endothelial growth factor and its soluble receptor (SFlt-1) in essential hypertension. Am J Cardiol 2001;87:805-807.

-11 Murohara T, Horrowitz JR, Silver M, Tsurumi Y, Chen D, Sullivan A, Isner, JM: Vascular endothelial growth factor/vascular permeability factor enhances vascular permeability via nitric oxide and prostacyclin. Circulation 1998;97:99-107.

-12 Zachary I, Mathur A, Yla-Herttuala S, Martin J: Vascular protection: a novel nonangiogenic cardiovascular role for vascular endothelial growth factor. Arterioscler Thromb Vasc Biol 2000;20:1512-1520.

-13 Nadar SK, Blann A, Beevers DG, Lip GYH: Abnormal angiopoietins 1 and 2, angiopoietin receptor Tie-2 and vascular endothelial growth factor levels in hypertension: relationship to target organ damage. A substudy of the Anglo-Scandinavian Cardiac Outcomes Trial (ASCOT). J Intern Med 2005;258:336-343.

-14 Bayorh MA, Mann G, Walton M, Eatman D: Effects of enalapril, tempol, and eplerenone on salt-induced hypertension in Dahl saltsensitive rats. Clin Exp Hypertens 2006;28: 121-132.

- 15 Catanzaro DF, Kurtz TW: Target organ damage in hypertension: mechanisms, prevention, and management. Am J Hypertens 2002;15:1117-1118.

-16 Rajagopalan S, Duquaine D, King S, Pitt B, Patel P: Mineralocorticoid receptor antagonism in experimental atherosclerosis. Circulation 2002;105:2212-2216.
17 Virdis A, Neves MF, Amiri F, Viel E, Touyz RM, Schiffrin EL: Spironolactone improves angiotensin-induced vascular changes and oxidative stress. Hypertension 2002;40:504510.

-18 Stier CT Jr, Benter IF, Ahmad S, Zuo H, Selig N, Roethel S, Levine S, Itskovitz HD: Enalapril prevents stroke and kidney dysfunction in salt-loaded stroke-prone spontaneously hypertensive rats. Hypertension 1989;13 115-121.

19 Ruggenenti P, Bettinaglio P, Pinares F, Remuzzi G: Angiotensin-converting enzyme insertion/deletion polymorphism and renoprotection in diabetic and nondiabetic nephropathies. Clin J Am Soc Nephrol 2008;3: 1511-1525.

20 Ruggenenti P, Perna A, Loriga G, Ganeva M Ene-Iordache B, Turturro M, Lesti M, Perticucci E, Nediyalkov I, Leonardis D, Garini G, Sessa A, Basile C, Alpa M, Scanziani R, Sorba G, Zoccali C, Remuzzi G: Blood-pressure control for renoprotection in patients with non-diabetic chronic renal disease (REIN-2): multicentre randomized controlled trial. Lancet 2005;365:939-946.

21 Keane WF, Zhang Z, Lyle PA, Cooper ME, de Zeeuw D, Grunfeld JP, et al: Risk scores for predicting outcomes in patients with type 2 diabetes and nephropathy: the RENAAL study. Clin J Am Soc Nephrol 2006;1:761767.

22 Remuzzi G, Macia M, Ruggenenti P: Prevention and treatment of diabetic renal disease in type 2 diabetes: the BENEDICT study. J Am Soc Nephrol 2006;17:S90-S97.

23 Rocha R, Martin-Berger CL, Yang P, Scherrer R, Delyani JA, MacMahon EG: Selective aldosterone blockade prevents angiotensin II/salt-induced vascular inflammation in the rat heart. Endocrinology 2002;43:48284836.

24 Nagase M, Shibata S, Yoshida S, Nagase T, Gotoda T, Fujita T: Podocyte injury underlies the glomerulopathy of Dahl salt-hypertensive rats and is reversed by aldosterone blocker. Hypertension 2006;47:1084-1093.

25 Aldigier JC, Kanjanbuch T, Ma L, Brown NJ, Fogo AB: Regression of existing glomerulosclerosis by inhibition of aldosterone. Am Soc Nephrol 2005; 16:3306-3314.

26 Kroll J, Waltenberger J: A novel function of the vascular endothelial growth factor receptor-2 (KDR): rapid release of nitric oxide in response to VEGF-A stimulation in endothelial cells. Biochem Biophys Res Commun 1999;265:636-639.

27 Mechtcherriakova D, Wlachos A, Holzmuller H, Binder BR, Hofer E: Vascular endothelial growth factor-induced tissue factor expression in endothelial cells. Blood 1999;93: 3811-3823.
28 Foster RR: The importance of cellular VEGF bioactivity in the development of glomerular disease. Nephron Exp Nephrol 2009;113:e8e15.

29 Tsai WC, Li YH, Huang YY, Lin CC, Chao $\mathrm{TH}$, Chen JH: Plasma vascular endothelial growth factor as a marker for early vascular damage in hypertension. Clin Sci 2005; 109: 39-43.

30 Ferrara N, Davis-Smyth T: The biology of vascular endothelial growth factor. Endocr Rev 1997; 18:14-25.

31 Kroll J, Waltenberger J: VEGF-A induces expression of eNOS and iNOS in endothelial cells via VEGF receptor-2. Biochem Biophys Res Commun 1998;252:743-746.

>32 Hood JD, Meininger CJ, Ziche M, Granger HJ: VEGF upregulates ecNOS message, protein, and NO production in human endothelial cells. Am J Physiol 1998;274:H1054H1058.

33 Shen B-Q, Lee DY, Zioncheck TF: Vascular endothelial growth factor governs endothelial nitric-oxide synthase expression via a KDR/Flk-1 receptor and protein kinase C signaling pathway. J Biol Chem 1999;274: 33057-33063.

34 Dembinska-Kiec A, Dulak J, Partyka L, Huk I, Mailnski T: VEGF nitric oxide reciprocal regulation. Nat Med 1997;11:1177.

35 Tsumuri Y, Murohara T, Krasinski K, Chen D, Witzenbichler B, Kearney M, Couffinhal T, Isner JM: Reciprocal relation between VEGF and NO in the regulation of endothelial integrity. Nat Med 1997;8:879-886.

-36 Ghiso N, Rohan RM, Amano S, Garland R, Adamis AP: Suppression of hypoxia-associated vascular endothelial growth factor gene expression by nitric oxide via cGMP. Invest Ophthalmol Vis Sci 1999;40:1033-1039.

37 Stuhlmeier KM: Activation and regulation of Hsp32 and Hsp70. Eur J Biochem 2000; 267:1161-1167.

38 Li GC, Li LG, Liu YK, Mak JY, Chen LL, Lee WM: Thermal response of rat fibroblast stably transfected with the human $70-\mathrm{kDa}$ heat shock protein-encoding gene. Proc Natl Acad Sci USA 1991;88:1681-1685.

39 Morimoto RI, Tissieres A, Georgopoulos C: Progress and perspectives on the biology of heat shock proteins and molecular chaperones; in Morimoto RI, Tissieres A, Georgopoulos C (eds): The Biology of Heat Shock Proteins and Molecular Chaperones. Cold Spring Harbor, Cold Spring Harbor Laboratory Press, 1994, pp 1-30.

$\checkmark 40$ Tazi KA, Barrière E, Moreau R, Heller J, Sogni P, Pateron D, Poirel O, Lebrec D: Role of shear stress in aortic eNOS upregulation in rats with biliary cirrhosis. Gastroenterology 2002;122:1869-1877. 